\title{
Herramientas de acción-investigación artística durante el confinamiento por Covid-19 a partir de la obra Viaje alrededor de mi habitación de Xavier de Maistre
}

\section{Resumen}

Este artículo presenta una investigación y propuesta educativa sobre arte y literatura a través del libro de Xavier de Maistre, Viaje alrededor de mi habitación (1794). Se enmarca en el periodo de confinamiento social Ilevado a cabo entre marzo y mayo de 2020 en España, y ha sido diseñada e implementada en la asignatura Aprendizaje y Enseñanza del Dibujo Artístico del Máster en Profesorado de ESO, Bachillerato y Formación Profesional de la Universidad de Almería.

Se muestra una metodología que parte con el objetivo de desarrollar experiencias que estimulen al alumnado desde su individualidad y aislamiento, propiciando un aprendizaje reflexivo y práctico en época de pandemia mundial. Mediante la lectura escogida, se plantean tres actividades en torno al dibujo y al objeto que propician un proceso creativo donde el discente estimula su percepción espacial y sensorial, así como su capacidad creadora e imaginativa fuera del aula.

Paralelamente, este trabajo aborda a nivel teórico la cotidianidad de la habitación, tanto en la novela como en la realidad del estudiantado, suscitando un diálogo entre el aula y el taller que permite cuestionar el espacio educativo, el papel del docente y la conciencia de grupo. La variedad de perfiles que ofrece este Máster (artistas, diseñadores, arquitectos, etc.) ha permitido aportar nuevos enfoques sobre dibujo, escultura y procesos de enseñanza-aprendizaje en arte.

\author{
Manuel Pérez-Valero \\ Doctor en Bellas Artes. \\ Universidad de Almería, Almería, \\ España. \\ Correo electrónico: mpvalero@ual.es \\ 이 orcid.org/0000-0001-7410-6375 \\ Google Scholar \\ Manuel Bru Serrano \\ Doctor en Bellas Artes. \\ Universidad de Granada, Granada, \\ España. \\ Correo electrónico: bru@ugr.es \\ 다이.org/0000-0002-5796-3399 \\ Google Scholar
}

Recibido: noviembre 12 de 2020

Aprobado: junio 22 de 2021

Palabras clave:

confinamiento, dibujo, escultura, investigación educativa, propuesta didáctica basada en las artes. 


\section{Art-based action-research tools during confinement by COVID-19 based on the work Journey around my room by Xavier de Maistre}

\begin{abstract}
This article presents research and an educational proposal on art and literature through Xavier de Maistre's book Journey around my room (1794). It is framed in the period of social confinement carried out between March and May 2020 in Spain and it has been designed and implemented in the Learning and Teaching of Artistic Drawing subject of the Master in Teaching of ESO, Baccalaureate and Vocational Training at Universidad de Almeria.

A methodology that starts with the objective of developing experiences that stimulate students from their individuality and isolation promoting reflective and practical learning in times of global pandemic is shown. Through the chosen readings, three activities are proposed around the drawing and the object that promote a creative process where students stimulate their spatial and sensory perception, as well as their creative and imaginative capacity outside the classroom.
\end{abstract}

At the same time, this work addresses, at a theoretical level, the everyday life of the room, both in the novel and in the reality of the students, provoking a dialogue between the classroom and the workshop that allows questioning the educational space, the role of the teacher and the group conscience. The variety of profiles offered by this Master (artists, designers, architects, etc.) has made it possible to provide new approaches to drawing, sculpture and teaching-learning processes in art.
Key words:

confinement, drawing, sculpture, educational research, arts-based didactic proposal. 


\section{Introducción}

El arte y la imagen siempre se han nutrido de la palabra apoyándose a lo largo de distintas manifestaciones artísticas. Ya es lejana esa idea de una brecha entre ambas, al igual que también entre cuerpo y mente, bestia y alma, como dice Xavier de Maistre, escritor y personaje de la historia que se presenta. Los artistas, y los docentes, saben que esa fisura hace tiempo se convirtió en un puente que ayuda a encontrar experiencias provechosas en ambos campos, el terrenal y el de la ficción.

Esta propuesta surge en un momento social anómalo debido al Covid-19 y el decreto de Estado de Alarma por parte del Gobierno español que ha supuesto, entre otras cosas, el confinamiento de la población durante dos meses y medio. En abril de 2020, se confeccionó la metodología que se propone tomando como punto de partida la novela de Xavier de Maistre (1763-1852), Viaje alrededor de mi habitación (1794), un relato corto en primera persona (él mismo) bajo unas circunstancias similares a las de nuestro alumnado. Ambas sometidas a un aislamiento que les impone el esfuerzo de "viajar" por su habitación y fantasear e imaginar con lo cotidiano más allá de las cuatro paredes que limitan su encierro.

El confinamiento del protagonista ocurre en pleno siglo XVIII como consecuencia de la pena impuesta por las autoridades de Turín al retarse en duelo por cuestiones amorosas. Pero dado su rango de oficial del ejército, conde y noble se libra de la cárcel, conmutándole la pena por un arresto domiciliario de cuarenta y dos días. Allí, en su habitación, realiza un viaje mental cargado de recuerdos, experiencias, fantasía, ficción y realidad.

El trabajo basa su estructura en la condición cualitativa de la escritura de la novela, donde el autor describe con detalle consiguiendo elaborar en nuestra 
cabeza dichos elementos visuales. Su escritura proviene de una realidad que se alimenta de la imaginación y el recuerdo con un propósito en común: la comunicación. Comprender y usar el dibujo, la creación, la palabra y la educación como fuente comunicadora es un factor clave para que los ciudadanos interpreten críticamente y gestionen la información recibida para ser sujetos activos en la sociedad. Mejorando aquellas herramientas éticas con las que interpretar y reflexionar sobre los modelos sociales que reciben (SotoRomero, 2008).

Se configura un proceso de investigación que no puede ir separado de la enseñanza, de ser así se correría el riesgo de resumir todo a unas actividades superficiales que solo repetirían lo ya existente (Ordine, 2013). Existen suficientes motivos para preocuparse por la calidad de la enseñanza y la investigación, así formaremos estudiantes comprometidos intelectualmente con lo que hacen, mediante producciones que sirven como reflexión sobre su propio papel en relación con el mundo y su obra, hablar de sí mismos (Ovejero, 2014). Entender campos como el literario, el radiofónico e incluso el televisivo como medios artísticos (no solo técnicos) que promueven la formación de nuevas posibilidades estéticas para generar lenguajes personales y autónomos (Eco, 2006). Como señala Salido-López (2017), nos debemos centrar en formar docentes críticos y creativos, fusionar distintas habilidades de los lenguajes artísticos con las capacidades que permitan conocer contextos que circulan en torno a la obra de arte.

\section{Nuevas posibilidades de investigación en arte y educación a través de la palabra y el dibujo}

El arte es una forma de conocimiento compleja que ayuda a hacer conexiones, las cuales activan nuestra razón, especulación y crítica. Con la imagen y la palabra surgirá un proceso de teatralización en el que el dibujante interpreta 
su propia particularidad percibida (Gómez et al., 2003). La educación artística está conectada al conocimiento como tal, no solo al que proviene del mundo visual. El análisis de imágenes es algo tan propio de la sociedad moderna que se relaciona en cualquier esfera de la educación.

Se desea que llegue un momento donde los términos "educación artística" no se pronuncien por separado. Donde la pedagogía y el arte se conformen análogamente y las obras generadas se empleen como dispositivos que activen un conocimiento reflexivo, desarrollando así sensibilidad didáctica. Una constante donde el arte tiene la necesidad de acercarse a la inteligencia emocional, binomio que la neuroeducación incorporaría al aula como una solución para ampliar la formación del alumnado (Acaso y Megías, 2017) y el profesorado (Costa-Rodríguez et al., 2021).

A través del arte y la educación se consigue conectar con la sociedad y entrar en un proceso de transformación. Siendo nuestro objetivo conocer nuestra comunidad globalizada, la cual, debido al confinamiento, parece tender al individualismo. El dibujo, el objeto, lo manual, toma interés ante el panorama digital y privado donde nos encontramos con las videollamadas, el teletrabajo y las plataformas.

Y es que, durante la infancia, el dibujo y la imaginación están muy presentes. Son acciones Ilenas de espontaneidad que con la llegada de la adolescencia se van perdiendo; preocupa más imitar bien que interpretar. Quizás porque el mundo académico concibe el dibujo como una técnica y no como una disciplina intelectual que desarrolla el pensamiento y la comunicación. Así, trabajando la inventiva y la curiosidad en las aulas, el estudiante estimula su imaginación y aporta nuevas posibilidades ante los problemas que se le planteen (Arnheim, 1993). El proceso creativo brota 
desde la búsqueda y la intuición, algo común a todas las ciencias, y el dibujo se presenta como fuente de recursos técnicos y conceptuales.

\section{Posibilidades del dibujo hoy. Herramienta sensorial de experimentación}

Cuando abordamos la práctica del dibujo en el aula, resulta interesante enfocarla como una vía de exploración y experimentación que evite la disyuntiva de si el resultado es correcto. El artista Patricio Cabrera, por ejemplo, describe esta forma de trabajo como dibujos de ensayo en A través del dibujo (Cano y Tovar, 1995). Son tanteos que demuestran el fluir de las ideas, huellas del proceso que supone aproximarse aún más al autor, una tipología de obra que él distinguía del dibujo "acabado" como tal.

Convendría no caer en el debate sobre una forma correcta de dibujar porque la valoración de los trabajos según su acabado puede resultar arbitraria. En este sentido, Moreno (2010) cuestionaba: “¿Cómo deducir escalafones valorativos de 'calidades plásticas'? ¿Cómo suponer valores indiscutibles deducidos de nuestro particular juicio? (...) ¿Cómo decidir grados de magisterio y perfección?" (p. 54).

Es más bien la idea de desafiar las reglas para construir nuevas visiones y formas de expresión, pues cada norma posee características que pueden llevarnos a diversas experimentaciones. Tratar de ver no solo con los ojos, ya que todos los sentidos estructuran y condicionan el proceso y resultado del producto. Con el dibujo completamos la realidad que no existe, esa que está en nuestro interior y que podemos reinterpretar. Imaginación, conciencia y creatividad para proyectar el futuro e ir más allá de sí mismo y sus sentidos (De la Torre, 2003). 
En una nota titulada Alimento para los jóvenes pintores, y con ese espíritu explorador que citábamos, Durero dedicó unas palabras a las promesas del arte renacentista: "Si enciendo una llama a todo lo que significa un progreso y un perfeccionamiento en el arte, es posible que con el tiempo se produzca una fogata que ilumine el mundo entero" (Friedenthal, 1963, p. 66). Este artista destacó en el dominio de la forma y su pasión por la observación, adoptando el dibujo como una herramienta con la que conocer el mundo. Hoy en día, la mayoría de los jóvenes se lanzan al vacío del papel sin miedo y encuentran el dibujo como un medio honesto, atrevido y abierto a toda experimentación. Y es que, como apuntaba Berger (2009), la superficie blanca del papel es como un espacio vacío lleno de posibilidades. Plantándose así ante el proceso creador con disposición al hallazgo y la sorpresa, a la serendipia misma, donde los logros, accidentes o casualidades se incorporan a la obra por dar en el clavo de lo que el artista iba buscando (Barro, 2012).

El dibujo se establece en los confines del significado, y cuando no quedan palabras, surge el dibujo. Nuestra mente parece estar diseñada para sentir satisfacción cuando "controla" los conceptos, cuando damos con una palabra para algo que antes no la tenía o cuando somos capaces de encontrar una imagen en una mancha abstracta o pareidolia (Bru, 2015). En contra de esa estabilidad, podemos sentirnos inquietos cuando el significado no se percibe tan claramente, resulta críptico o simplemente desconcertante (Jiménez, 2009). Precisamente en ese territorio ha sido donde el dibujo ha tomado fuerza, germinando en los entresijos del arte y el significado desde la sencillez más absoluta.

\section{Fantasía e imaginación durante el confinamiento. La imagen como relato}

Con la lectura, se pretende promover la creación e interpretación al activar relatos visuales que sugieran nuevas formas de concebir su confinamiento. 
Esta manera de narrar mediante imágenes genera una trama en sí que propicia nuevos estados de imaginación. Todo ello unido al dibujo, el cual supone una prolongación del pensamiento, así nuestra mente guía la mano sobre el papel a la vez que ese dibujo emergente configura una nueva imagen mental (D. K. Ching, 2012).

La imaginación se convierte en el instrumento que sirve para sumergir activamente al lector, no solo a interpretar sus palabras, sino que además se convierte en protagonista por la similitud social de las circunstancias. El discente, un invitado más en la habitación de Maistre, se transforma en creador de imágenes y con su imaginación abre los ojos y (re)descubre (Jenny, 2013). En ese descubrimiento, el alumnado debe tener una actitud abierta a la hora de ver, pensar y recordar. Aprender a percibir esa nueva realidad que le ofrecen las imágenes-recuerdo que afloran al encontrarse con los objetos (Simondon, 2013).

Pero la fantasía, como bien defiende Munari (2018) en Fantasía. Invención, creatividad e imaginación en las comunicaciones visuales, también tendrá un papel importante en las representaciones del alumnado. Al ser una facultad más libre que la imaginación, puede llegar a pensar cualquier cosa, por absurda o increíble que parezca. Incluso ignorando la posibilidad de que lo pensado funcione, ofreciendo la libertad de fantasear. Esto dotará a los resultados de una gran variedad técnica y comunicativa. Según Barthes (1982), "toda imagen es polisémica; implica — subyacente a sus significadosuna cadena flotante de significados, entre los cuales el lector puede elegir algunos e ignorar otros" (p. 35).

La escritura recuerda las narraciones características de esa época, con viajes increíbles y fantásticos, y se aproxima a ellas con actitud irónica, la misma que posee en su habitación. En un estado de embriaguez y ensueño, la transforma 
en un lugar apetecible y provechoso. Durante su confinamiento también le dio tiempo a aburrirse y a desesperarse, al fin y al cabo el protagonista es como nosotros. Pero esta historia va más allá debido al viaje que plantea, y lo más atrayente es su poder de reflexión, su carácter psicológico y su validez didáctica en estas circunstancias. El alumnado debe entender la importancia que posee el acto de convertir las palabras y las ideas en líneas, manchas o trazos sobre un papel. Esta acción estimula la mente y por consiguiente libera la imaginación, fomentando así su pensamiento creativo (Lambert, 1996).

No obstante, nuestro confinamiento es algo distinto al que se desarrolla en las páginas de la novela. Es obligatorio y riguroso, en algunos casos familiar, en otros el retiro es solitario. Aunque algo similar es la forma de sobrellevarlo mediante una conducta lúdica y una disposición positiva e irónica hacia el propio yo.

\section{Del dibujo al objeto y del objeto al recuerdo. La imagen como reflejo y memoria}

La habitación se constituye no solo como lugar sino también como un reflejo de nuestro universo personal. Incluso el de otros, como bien supo captar el artista Edward Hopper en sus composiciones cuando combinaba la presencia de personas, objetos y el potencial narrativo de los interiores. Así se aprecia en Morning sun (1952) o A woman in the sun (1961), habitaciones que resultan protagonistas de la escena misma, más allá de la presencia de esas mujeres de mirada perdida.

Las descripciones realizadas por Maistre hacen hincapié en el mundo objetual que le rodea, un recurso narrativo que le posibilita divagar y ahondar en la importancia de las cosas. Exhibición de la intimidad que recuerda a la intensidad de Van Gogh a la hora de pintar y describir su entorno en muchas 
de sus obras. Así se recoge, por ejemplo, en "El interior expuesto. Sobre la habitación de Van Gogh en Arlés (óleo sobre lienzo, 72 x 90 cm, 1888)" del arquitecto Chávez (2013):

La perspectiva logra describir un ámbito incluyente del mundo personal de un individuo al manejar múltiples puntos de fuga para concentrar la percepción visual en cada uno de los objetos de la pintura. Así, la realidad se percibe como un conjunto de artefactos que poseen su propia autonomía constitutiva y ontológica, y que establecen un sistema de relaciones único para determinar un universo con sus cualidades particulares. (p. 199)

Debemos comprender la importancia cultural de aquellos objetos que empiezan a concebirse por su carga emocional. Objetos que se perciben como inútiles, pero que sin embargo no desaparecen de nuestra vida cotidiana, se podrían llamar de "recuerdo" y adquieren sentido atendiendo a su trascendencia. Así lo objetual se presenta de un modo personal considerando las experiencias vividas (Martín, 2002), ya que nuestra percepción reconoce en ello creencias comunitarias y biográficas a las que pertenecemos como sociedad.

Teniendo en cuenta estas palabras, es aquí donde las cosas más superficiales de la habitación recuperan su poder, ilustrando el tipo de sociedad que vivimos. Serían nuevos objetos más allá de lo estético, irónicamente sencillos y puros, como también lo han sido las imágenes de Andy Warhol para la colectividad (Baudrillard, 2012). Acercar la importancia del objeto al estudiante es acercar el arte contemporáneo a su conocimiento. Como, por ejemplo, conocer que la mayoría de obras que fueron despreciadas, incomprendidas e incluso no reconocidas como arte, han sido obras objetuales. Y que, como sostiene Walter Benjamin (2012), aquello que la sociedad ha hecho, otros pueden volver a hacerlo, aportando a la obra de arte el carácter reproducible tan cuestionado por el mercado. 
Por lo tanto, el interés hacia el objeto en esta investigación consigue hacer un reflejo histórico, social y cultural de una etapa específica del alumnado. Pronto se desbordan los límites de aquellos escogidos para expandirse por campos de distinta índole, ya sea la acción, la reflexión, la desmaterialización o el propio proceso (Pérez-Valero, 2016). Asistimos a un auténtico cuestionamiento del objeto como tal. Hablamos de una nueva sensibilidad y forma de experimentar, apreciar y percibir las emociones y los conceptos. La realidad de la habitación del estudiantado es subjetiva, y como espacio de creación que es nos servirá para producir y declarar arte.

Fue durante el siglo XIX donde el objeto se involucra directamente en nuestras vidas, o más bien, es la propia vida del objeto la que se apodera de todos nuestros escenarios, tanto personales como creativos. Adorno (2007) señalaba que el contexto en el que operan estas nuevas imágenes y objetos puede ejercer una labor restrictiva en el individuo. Esta relación se acaba fundiendo con la cultura de masas, propia del siglo XX, y su particular obsesión por el consumo. Se nos presenta una sociedad cuya expansión capitalista incide directamente en la construcción del "yo" (Maiso, 2019).

En esta propuesta se han tomado elementos cotidianos para transformarlos en esculturas. El nuevo bodegón del arte contemporáneo ahora es corrosivo, incluso amoral, como puede serlo una cama o una tienda de campaña (Emin, 1995, 1998), ambos con características similares a la habitación. Lo importante es saber apartarse de sentimientos comunes, autoeducarnos no solo como productores, también como espectadores. Este aprendizaje comienza en nuestra educación emocional, educar a través de la duda, el descubrimiento o lo inadecuado. Esto ayudará a entender el potencial de los objetos, saber que pueden llegar a ser mucho más de lo que ya son, proporcionando nuevos campos de investigación-acción artística. 
Con la pluralidad de esta metodología (investigar-actuar) se ofrecen al futuro profesorado diversas posibilidades de reflexión y actuación que le hacen indagar en los procesos revisados previamente (Fernández y Johnson, 2015). Desde este enfoque, Latorre (2003) sostiene que:

La reflexión en la acción se constituye (...) en un proceso que capacita a las personas (...) a desarrollar una mejor comprensión del conocimiento en la acción, ampliando la competencia profesional (...) pues la reflexión en la acción capacita a los profesionales para comprender mejor las situaciones problemáticas y les reconoce la habilidad para examinar y explorar las zonas indeterminadas de la práctica. (p. 19)

La creación artística no solo depende de cómo se haya conseguido elaborar la imagen, sino también de su contexto, posición y título. Una forma de crear un vínculo entre el objeto y el espectador es a través del enunciado, retornando de esta forma a la palabra, donde puede ser más importante la información que el objeto en sí. De esta manera, el alumnado amplía sus aptitudes en función de cómo evolucionen sus necesidades e intereses, acto determinante de una sociedad que grita un "cambio de época" y no una "época de cambios" (Prados, et al., 2018).

\section{Más allá del aula. La habitación como laboratorio para el alumnado}

Esta propuesta está destinada a despertar una nueva conciencia mediante la situación de confinamiento, asombrándonos durante un viaje (casi) inmóvil. Es esencial entender esa dualidad indisoluble entre alma y bestia para conocer la inclinación del protagonista, así nos sumergiremos en la parte más existencial de nuestro ser. Sin duda, esta obra literaria es un homenaje a nuestra imaginación y al lugar que uno habita. Sus palabras invitan a crear, entendiendo este acto no como resultado, sino como un elemento más del proceso, de la fabricación y, por tanto, de la metodología. Este aprendizaje basado en la creación apunta a la importancia de la acción 
reflexiva, cognitiva y sensitiva como experiencia generadora de producto (Caeiro-Rodríguez, 2018).

En un tiempo donde la libertad de raciocinio parece estar cuestionada, la letra y la imagen se convierten en pura necesidad. No es igual decir que contar, del mismo modo que dibujar no es copiar. Hablamos de ejercicios que requieren del recuerdo de experiencias mentales que se verifican en el plano visual al ser representadas plásticamente. Los recursos visuales y narrativos se asemejan a la poética de mensajes gráficos que ayudan a algo tan importante como es la comunicación, aquí también podemos advertir el papel tan importante que juega el arte en la educación.

Y no es que nuestra intención sea únicamente destacar la educación artística, sino que va dirigida a la educación en su sentido más amplio. En las instituciones, aunque a pasos muy lentos, ya se va entendiendo el campo de las artes como una importante fuente de experimentación, reflexión y comunicación. Debido a la situación de encierro, podemos confirmar cómo la cultura es la causante de nuestro despertar, fruto de estímulos y pensamientos que nos hacen superar tan complicada y peculiar experiencia. Poniendo a prueba la capacidad del alumnado y del docente, para ajustarse a nuevas metodologías de enseñanza-aprendizaje que transformen una situación de crisis en un estado potencial de creatividad (Borrero, 2021).

Aquí juega un papel importante la inteligencia emocional para ayudarnos a identificar, comprender y manejar nuestras emociones en relación con el contexto de Covid-19 (Extremera, 2020). Pues con el cierre de escuelas e instituciones académicas el sistema educativo casi desaparece o queda en su mínima expresión (Murillo y Duk, 2020). Esto implica (re)construir una educación que "nos cuide". A veces es difícil sostener cómo lo artístico supone un eslabón superior del progreso cuando la sociedad cuestiona la idea misma 
de evolución dentro de nuestra civilización. Por ello, debemos ser conscientes de que es imposible o poco probable que exista un arte universal para todas las culturas y personas (Efland et al., 2003).

\section{La percepción interdisciplinar. Del texto visual a la imagen textual}

Cualquier forma, palabra, imagen, color, símbolo o textura, ayuda a activar nuestro pensamiento visual, a exteriorizar e interpretar aspectos diferentes en cosas que conocemos. Este proceso tan enriquecedor se debe a la acción de asociar o pensamiento asociativo. Esta situación no solo está presente en el campo del dibujo; los surrealistas literarios ya utilizaban en sus creaciones el pensamiento divergente y asociativo entendiendo la palabra como un campo contiguo donde la vida (la realidad, lo cotidiano) encuentra su verdadera realización (Breton, 1992). Metodologías experimentales que sería interesante incluir en las aulas y no dejar que sea únicamente fuera de clase cuando las normas se rompan, educando al alumnado para que dilate sus límites con crítica y razonamiento.

Con la propuesta planteada, se pretende que el futuro profesorado conozca la libertad interdisciplinar existente al leer un libro y observar una imagen. Porque no todo son palabras y dibujos, también existe la interpretación subjetiva como observadores. Una observación que centra su interés en los sentidos como agentes interpretativos más allá de la vista. Estos serán los principales instrumentos para conseguir creaciones verdaderas cargadas de emoción y significado (Escobar, 2000). Hablamos de una educación artesanal, como diría Acaso (2017), una forma de entender la pedagogía totalmente contraria a lo que Ilamaríamos educación industrial. Donde no existe separación entre lo intelectual y lo emocional. Esta investigaciónacción artística ayuda al alumnado a perfeccionar su percepción y tiene 
como objetivo enseñar a aprender, a configurar y expresar el pensamiento visual, haciendo de la lectura y el juego el camino para alcanzarlo.

Trabajar el pensamiento visual es beneficioso y cultivarlo de manera interdisciplinar ayuda a conseguir un tipo de destrezas que no solo son útiles en profesiones puramente creativas, ya que en cualquier campo es imprescindible manejar diferentes tipos de interpretaciones para resolver problemas. Con la experiencia realizada mostramos cómo el ojo humano es capaz de percibir de manera particular y cómo completa el conjunto usando conexiones imaginarias que dan forma a un todo que parecía disperso (Munari, 2016).

\section{Metodología de la investigación-acción en educación artística}

Según la concepción de la habitación como espacio de creación, se invita al alumnado a percibir y representar su propia realidad sin la influencia del grupo. El espacio para trabajar ha sido su casa, cobrando así importancia la habitación como laboratorio-taller. Esta propuesta se basa en el diseño y práctica de una experiencia educativa para la enseñanza-aprendizaje de las artes visuales y plásticas desde planteamientos pedagógicos de carácter crítico y comprometido, como alumnado y futuros docentes (Cánovas, 2015). Así, el proceso de investigación se fundamenta en la misma producción artística como acción creadora (Barone y Eisner, 2012). La investigación artística, desde un planteamiento didáctico, se transforma en un "espacio social de producción de pensamiento y conocimiento" (Hernández et al., 2019, p. 30).

La propuesta ha sido diseñada para un grupo de 18 personas (12 alumnas y 6 alumnos), de entre 23 y 40 años, en la asignatura Aprendizaje y Enseñanza del Dibujo Artístico del Máster en Profesorado de Educación Secundaria Obligatoria y Bachillerato, Formación Profesional y Enseñanza de Idiomas 
(especialidad Dibujo, Imagen y Artes Plásticas). Realizar la experiencia con un número reducido de alumnado ha sido fundamental para poder trabajar en profundidad los distintos aspectos conceptuales de la propuesta. Los espacios de trabajo utilizados han sido las propias habitaciones del alumnado en sus respectivos hogares y la plataforma virtual Blackboard Learn de la Universidad de Almería.

Esta experiencia didáctica consiste en la lectura del libro de Maistre y la realización de tres acciones distintas para llevar a cabo posteriormente, todo ello en un periodo de 13 días, del 13 al 26 de abril de 2020. Se escogieron estas fechas por adecuarse a las vacaciones de Semana Santa fijadas en el calendario académico, para que el alumnado tuviese tiempo suficiente para la lectura, reflexión y desarrollo de las actividades. Estos tiempos no son cerrados o inamovibles, ya que podrían modificarse para adaptarlos, por ejemplo, a la enseñanza secundaria o bachillerato si se quisiera implementar esta propuesta docente en otro ámbito. A continuación, se detallan dichas fases o acciones creativas de conocimiento y de producción:

\section{$1^{a}$ Acción: La habitación}

El alumnado debe realizar un dibujo a mano alzada de la habitación descrita en la lectura, con grafito o bolígrafo sobre papel A4 o mediante tableta gráfica a nivel digital. Para su representación, se puede escoger el punto de vista que se prefiera, aunque se aconseja usar la perspectiva cónica por su buena capacidad descriptiva.

\section{$2^{a}$ Acción: La idea de envolver}

El objetivo reside, por un lado, en conocer la obra de Judith Scott, y, por otro, introducir el concepto de artista outsider y Art Brut y, seguidamente, consensuar 
qué significa para cada uno de los alumnos el concepto de envolver. Este acto tiene que ver con el tapar, proteger, cubrir, preservar o esconder, juntar o incluso enredar. La elección del outsider art como motor de creación se debe a que gran parte de este "arte marginal" refleja estados mentales extremos (como aquellos que se pueden desarrollar durante un confinamiento), elaborados como mundos particulares repletos de fantasía e imaginación. Además, se introduce la cama como otro protagonista de la imagen, pues es un objeto recurrente durante toda la lectura y enlaza con el contexto íntimo que engloba toda esta práctica. Escoger a Judith Scott es debido al aislamiento social que ella sufrió en primera persona, más cruel sin duda alguna del sufrido por nosotros en un confinamiento o por Xavier de Maistre en la novela. Nació con síndrome de Down y padece una sordera que tardó mucho tiempo en ser diagnosticada. La metodología ha sido la siguiente:

- Escoger un objeto inútil o innecesario y envolverlo (se puede usar cualquier material para envolver, como sábanas, ropa, papel higiénico, revistas...).

- Fotografiar el objeto envuelto sobre su cama.

- Escoger un título y explicar la intención de dicho gesto y por qué consideras ese objeto como algo trivial.

- Generar un documento con la imagen, título y texto.

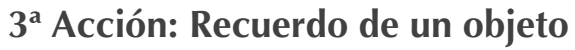

A partir del objeto anterior, dibujar su silueta en un nuevo papel A4 y, en su interior, representar un recuerdo vinculado a ese objeto. Para Ilevarlo a cabo, se recomendó que ese dibujo de línea de contorno realizado fuese de buen tamaño para luego incluir su escena rescatada de la memoria, ocupando todo el espacio circundante. Este nuevo dibujo se ha realizado con técnica libre. 
Respecto a la evaluación, se han tenido en cuenta los siguientes criterios:

- $\quad 1^{\text {a }}$ Acción. Se valorará positivamente la capacidad descriptiva frente a la calidad técnica, poniendo énfasis en el enfoque interpretativo e imaginativo de la atmósfera creada por el escritor.

- $\quad 2^{\mathrm{a}}$ Acción. La reflexión sobre el objeto seleccionado; la comprensión del lenguaje artístico de Judith Scott en el acto de envolver; la creación del objeto escultórico llevada a cabo; la calidad de la fotografía presentada (composición, encuadre, resolución).

- $\quad 3^{\text {a }}$ Acción. Aprovechamiento del espacio generado tras la silueta dibujada y la propuesta pictórica del recuerdo escogido (nivel técnico y creativo de la representación).

Los datos, los argumentos visuales y las conclusiones se fundamentan por las imágenes resultantes. Las cuales nos sirven para extraer una lectura, no solo técnica, también de carácter simbólico (Irwin y De Cosson, 2003). Por ello, y siguiendo las contribuciones de León y Montero (2015), se ha evolucionado hacia una metodología de observación y análisis con el fin de encontrar relaciones entre la representación plástica y el contexto vivido. Donde lo cotidiano se distorsiona y se entiende como el eje de creación y gestor de conocimiento crítico (Martín-Piñol y Calderón-Garrido, 2021).

\section{Análisis de los resultados}

En el siguiente apartado se presentan las imágenes derivadas de la experiencia, considerando los dibujos, esculturas y fotografías como resultados de la investigación junto con las aportaciones reflexivas del alumnado. La respuesta por parte de los participantes ha sido muy positiva, tanto por sus contribuciones artísticas como por el compromiso hacia la sociedad y el escenario educativo pandémico vivido durante la propuesta. 
Nos consta que la lectura del libro de Maistre ha supuesto una experiencia interesante y de buen agrado para el alumnado, destacando entre sus opiniones la idoneidad de la propuesta con el periodo de confinamiento. La respuesta del grupo ha sido muy buena, fruto de ello son la gran cantidad de trabajos que configuran por sí solos todo un entramado de conclusiones a nivel visual. Es decir, estos resultados son de carácter cualitativo, entendiendo la imagen como una fuente de información y valor cuyo objetivo es despertar el interés por lo que se cuenta.

En la Figura 1 se recogen dibujos del espacio que describe el autor en su libro y en el que se desarrollan los acontecimientos sucedidos a lo largo de la lectura. Si bien hay elementos comunes porque así se detallan en el libro, se observan distintos enfoques, atmósferas y perspectivas (sobresaliendo la de un solo punto de fuga). Algunos destacan por la gran cantidad de detalles representados y por captar con destreza ese ambiente decimonónico (Figura 2), otros proponen algo más decadente y oscuro (Figura 3) y también aquellos que llaman la atención por el punto de vista elegido (Figura 4). 

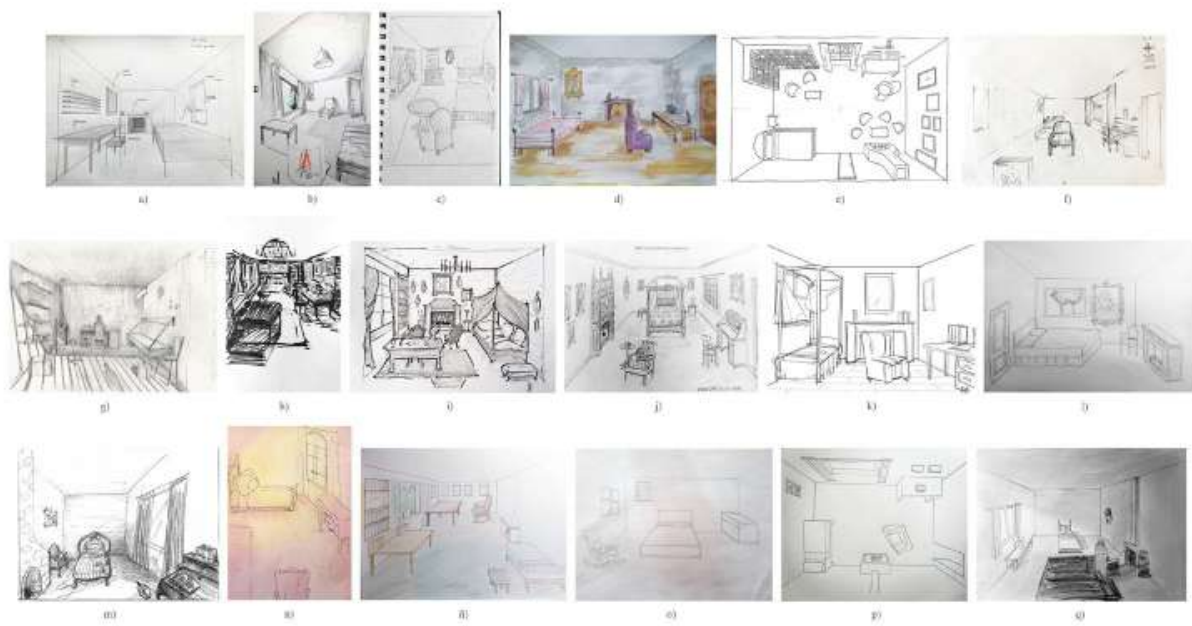

Figura 1. Obras de la 1ª acción: La habitación. Nota. a) Alfonso A.G. b) Antonio C. c) Brenda L. d) Carolina P.S. e) Cristina R.M. f) Daiana R.D.S. g) Dámaso C. h) Isabel G.S. i) José Carlos H.R. j) Juan José G.A. k) María del Pino M.T. I) María Dolores C. m) Natalia T.B. n) Patricia A. ñ) Raquel F. o) Raquel G.G.

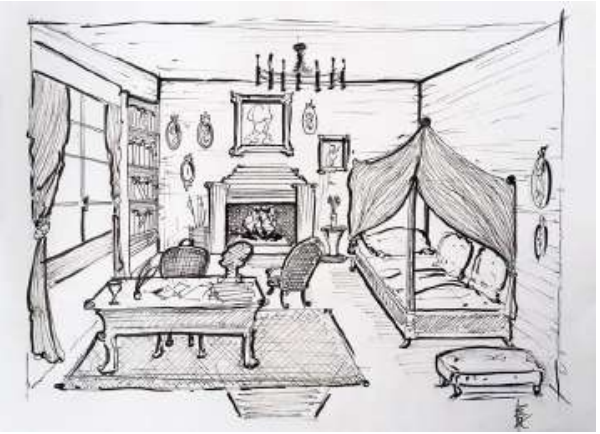

Figura 2. José Carlos H.R. Grafito y tinta sobre papel, 21 x 29,7 cm, 2020. 


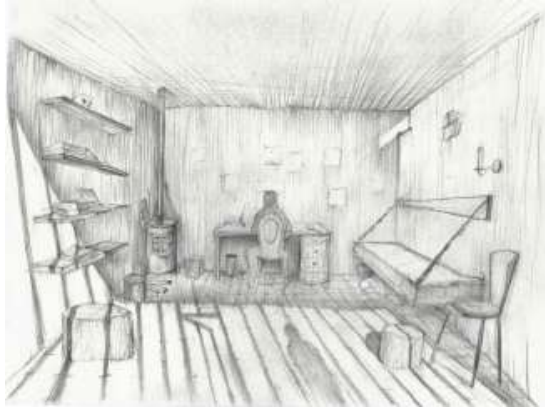

Figura 3. Dámaso C. Grafito sobre papel, 21 × 29,7 cm, 2020.

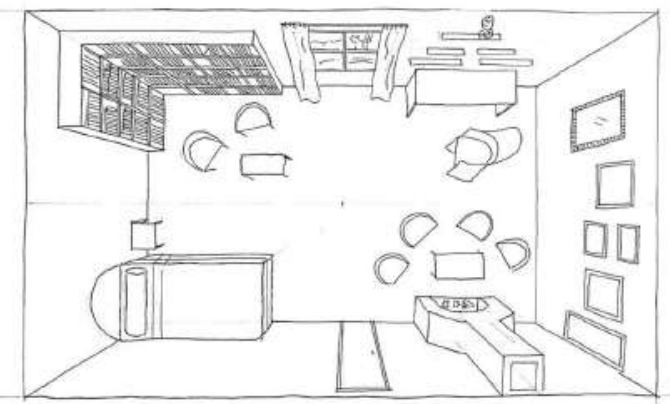

Figura 4. Cristina R. M. Tinta sobre papel, $21 \times 29,7$ cm, 2020 .

En ocasiones se hace evidente que, al plantear el trabajo desde el dibujo técnico y la proyección, los elementos que componen la escena tienden a sintetizarse. Los butacones surgen de cubos; las camas, de prismas; o algunas chimeneas como salientes rectangulares de las paredes. Otros dibujos, en cambio, se realizan con desenvoltura y un trazo más orgánico. Diferencias que pueden observarse rápidamente, por ejemplo, en los dibujos A y $\mathrm{H}$ de la Figura 1. No obstante, habría una tercera tipología que combinaría tanto la parte más técnica con la soltura, partiendo de líneas abocetadas para detallar posteriormente a mano alzada (dibujo B, Figura 1). Este es un hecho que pone de relieve la variedad de estrategias de representación y ordenación del espacio que tiene cada estudiante (diferencias que se unen a otras como los distintos tipos de grafismo, concepción del mobiliario, nivel de detalle o claroscuro).

Pero también existen semejanzas a la hora de llevar a cabo sus obras. Y es que un aspecto común en gran parte de ellas es que se aprecia que los autores se han ayudado a veces de fotografías para dibujar los objetos. A pesar de recrear un espacio imaginario, el estudiante emplea referencias de lo real para construir la imagen. Un recurso que también observaremos durante la tercera actividad. 
La segunda de las actividades (Figura 5), suponía un salto a la habitación misma de cada participante y la oportunidad de localizar un objeto de su propia realidad para exponerlo al resto del grupo y al profesorado. Un juego "de dentro hacia afuera" en el cual, aun tratándose de objetos cotidianos y casi olvidados en una estantería, adquirían una nueva entidad al ser escogidos, envueltos (manipulados de nuevo tras largos años de olvido) y mostrados en el pedestal privado que es una cama (ver Figuras 6, 7, 8).
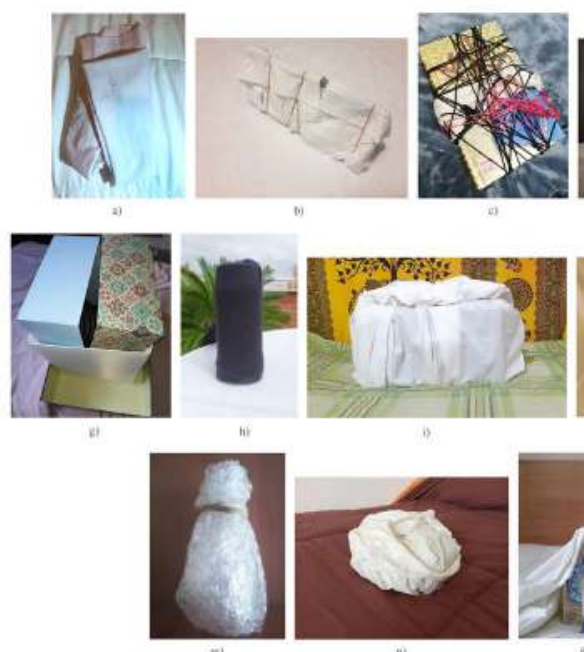
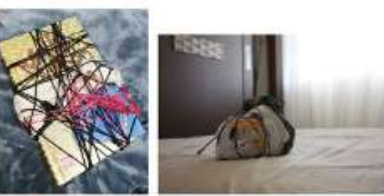

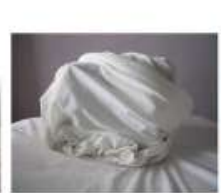

s)
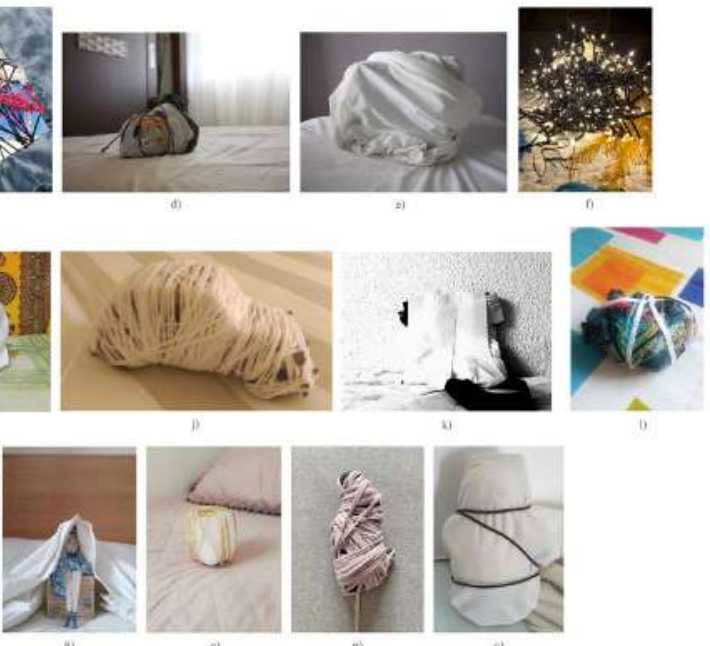

s)

Figura 5. Obras de la $2^{a}$ acción: La idea de envolver. Nota. a) Alfonso A.G. b) Antonio C. c) Brenda L. d) Carolina P.S. e) Cristina R.M. f) Daiana R.D.S. g) Dámaso C. h) Isabel G.S. i) José Carlos H.R. j) Juan José G.A. k) María del Pino M.T. I) María Dolores C. m) Natalia T.B. n) Patricia A. ñ) Raquel F. o) Raquel G.G. p) Rosa R. q) Víctor G. 


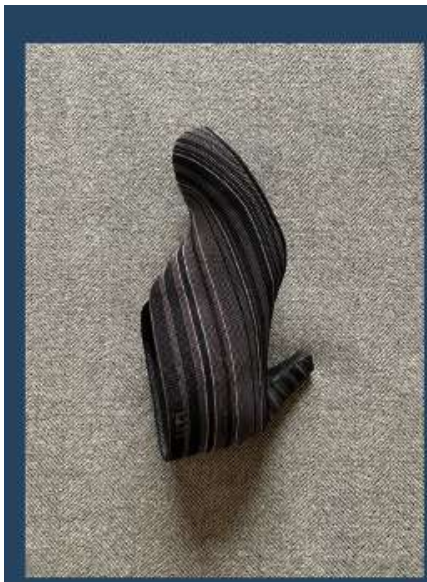

\section{EL ZAPATO COMO ELEMENTO SIMBÓLICO

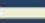 \\ En nuestra sociedad occidental se usa el zapato de \\ tacón para realzar el pecho y las nalgas, alargar las piernas, atraer al hombre,..son \\ una mentira, que empodera a las mujeres a cambio de convertirlas en sumisas a \\ los convencionalismos. \\ aumentando el riesgo de \\ afecciones esqueléticas. \\ musculares, juanetes y dolor.}

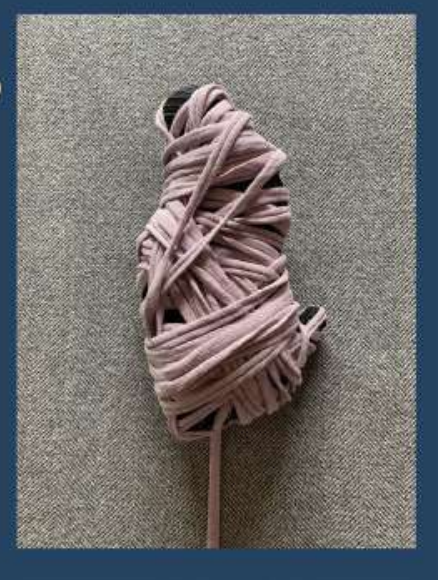

Figura 6. Rosa R. Zapato y cordoneras, 2020

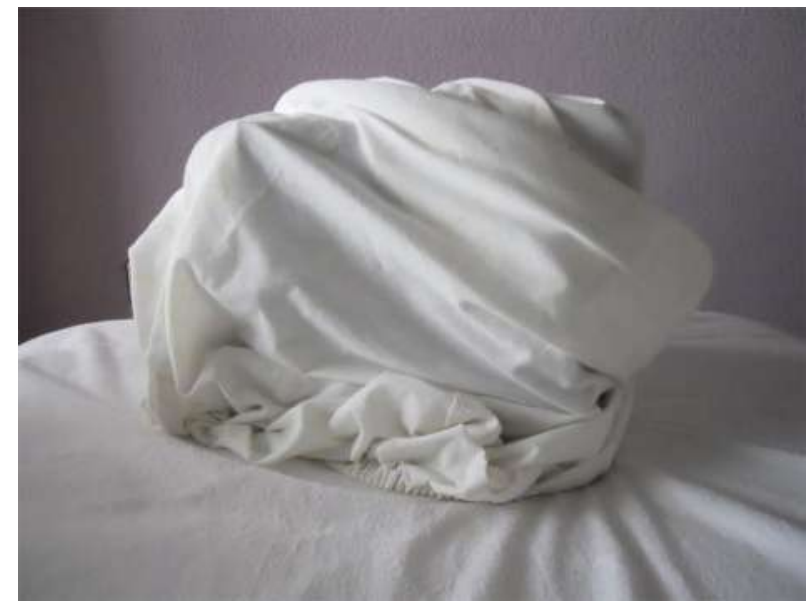

Figura 7. Cristina R. M. Palabras olvidadas, enciclopedia envuelta en tela, 2020. 


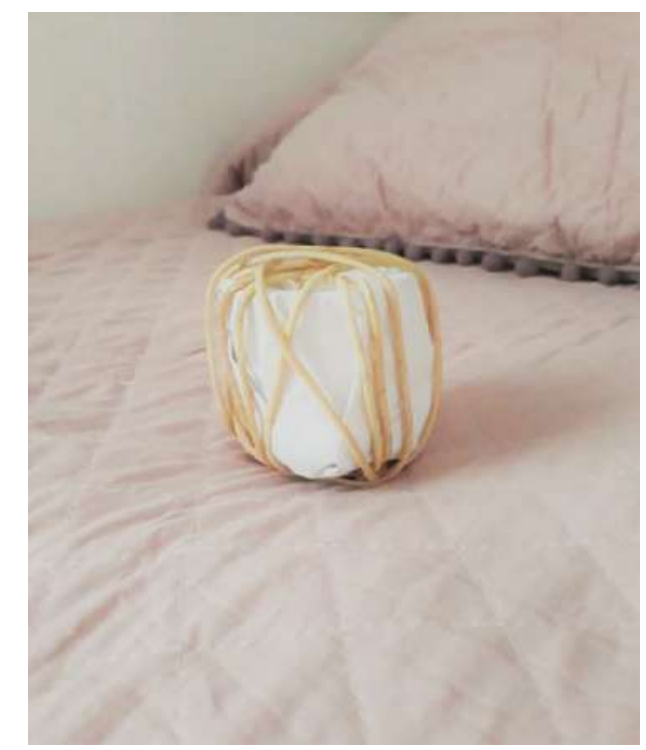

Figura 8. Raquel G.G. A oscuras, vela envuelta en papel y cuerda, 2020.

La tercera acción (Figura 9) propiciaba un juego entre contenido y silueta que ha dado como resultado una serie de obras sugerentes por el hecho de adecuar un dibujo a una forma. Esto posibilitaba, por un lado, que el alumnado se adaptara a una configuración específica y no al tradicional formato A4, dando pie a una creativa búsqueda de soluciones; por otro, estas formascontenedor modifican la composición general de la obra e introducen un elemento impuesto por la actividad y que no elige (o encuentra) el alumnado, alterando el proceso creativo para volverlo más interesante y productivo (ver Figuras 10, 11 y 12). 

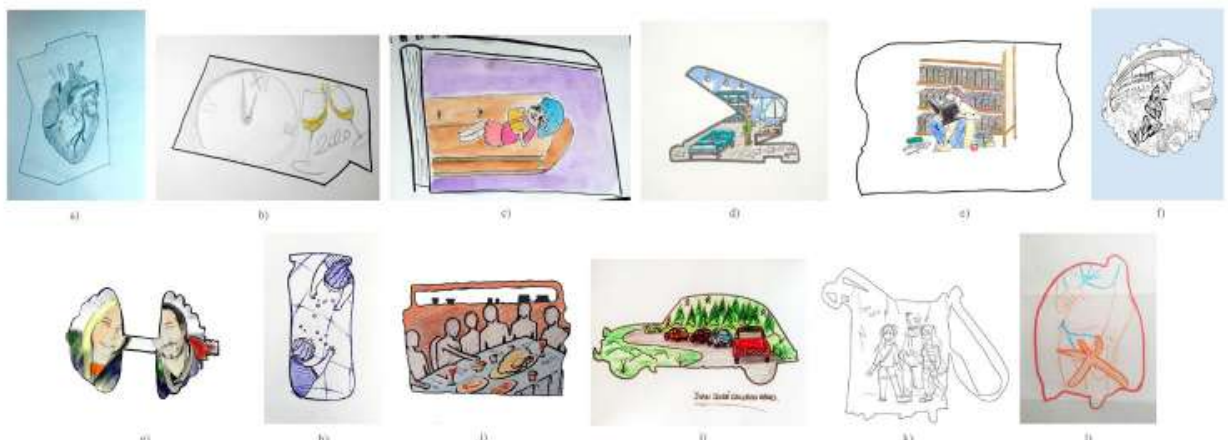

(t)

II
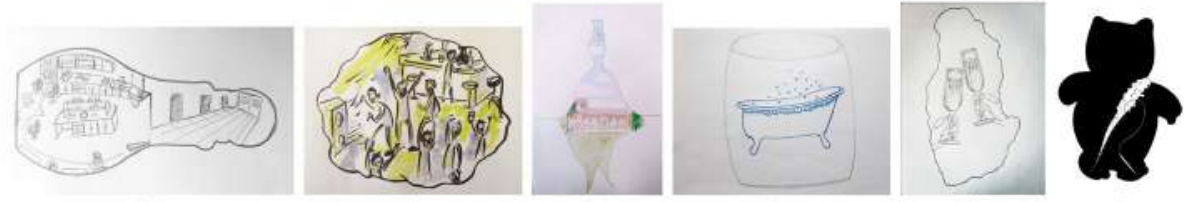

Figura 9. Obras de la $3^{\text {a }}$ acción: Recuerdo de un objeto. Nota. a) Alfonso A.G. b) Antonio C. c) Brenda L. d) Carolina P.S. e) Cristina R.M. f) Daiana R.D.S. g) Dámaso C. h) Isabel G.S. i) José Carlos H.R. j) Juan José G.A. k) María del Pino M.T. I) María Dolores C. m) Natalia T.B. n) Patricia A. ñ) Raquel F. o) Raquel G.G. 


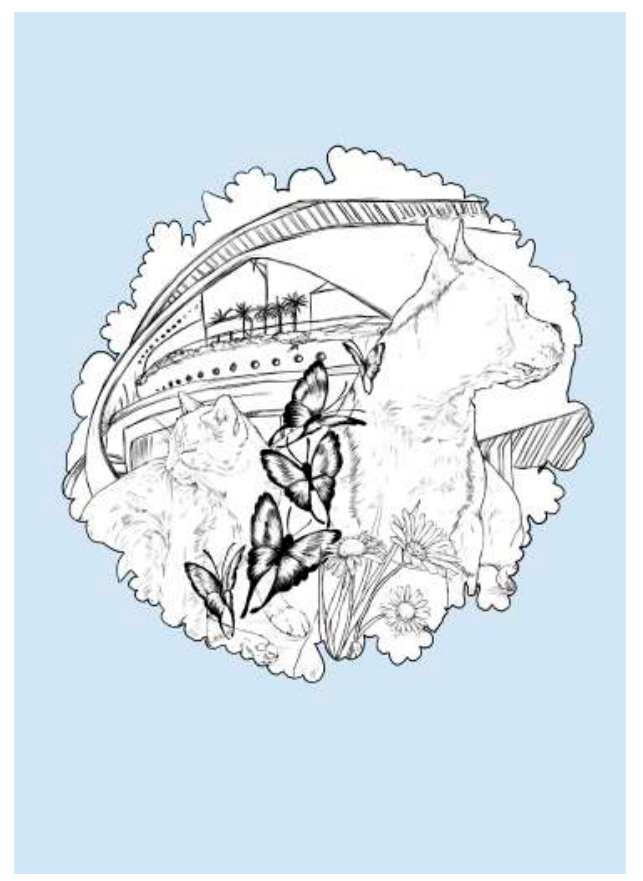

Figura 10. Daiana R.D.S. Dibujo digital, 2020

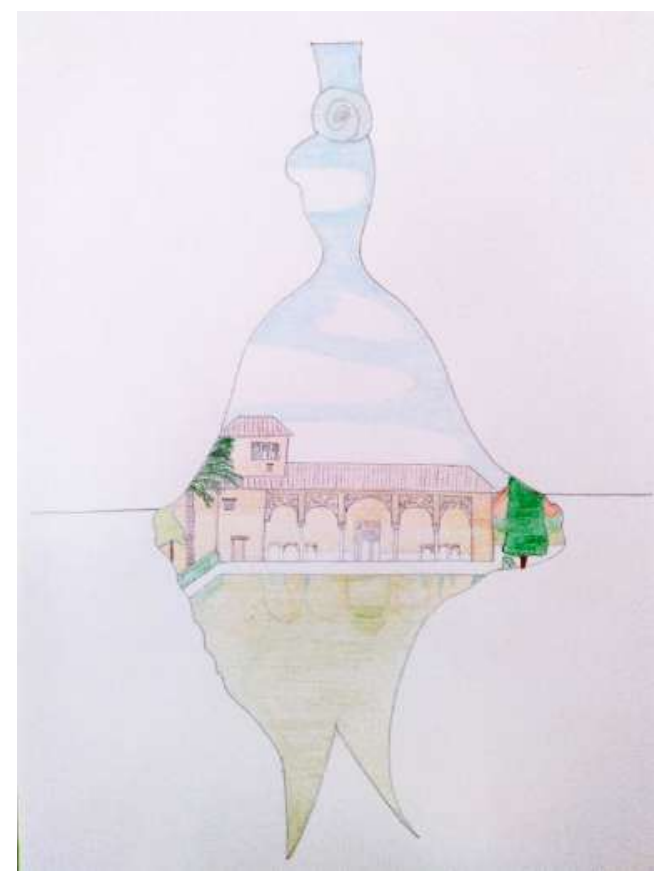

Figura 11. Raquel F. Grafito y lápices de colores sobre papel, $21 \times 29,7 \mathrm{~cm}, 2020$. 


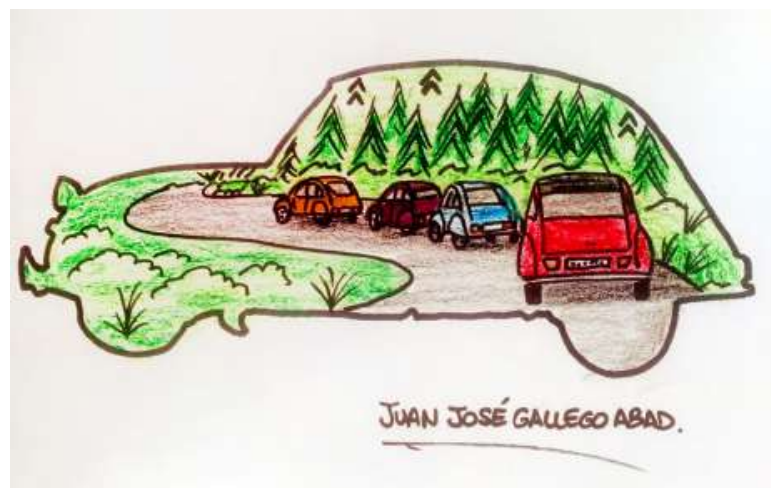

Figura 12. Juan José G.A. Rotulador y lápices de colores sobre papel, 21 x 29,7 cm, 2020.

A rasgos generales se observa una tendencia al equilibrio conceptual entre la imagen, el recuerdo y el objeto, profundizando en el trasfondo social. Sus claves más características son la correlación visual entre recuerdo y realidad, la sorpresa ante el potencial del objeto cotidiano como iconografía social y la preferencia por alterar los usos comunes de las cosas. Sus creaciones nos presentan cómo lo objetual se acerca más a la conceptualidad que a la técnica o la materia. Cada opción surge por la necesidad individual de comunicar un recuerdo, una emoción o sensación.

Observamos, tanto en los dibujos como en los objetos artísticos, iconografía proveniente de la cultura popular. Por ello, durante la experiencia, se ha considerado el arte contemporáneo como una representación cultural que forma parte de su realidad y sus vivencias. La propuesta confirma cómo, a partir de los objetos y sus recuerdos, se producen reflexiones críticas en relación a problemas específicos y cuestiones que van más allá de los contenidos tradicionales revisados en un aula. Los trabajos evidencian la necesidad de potenciar el pensamiento creativo, la comunicación visual y la crítica. 
Destaca la trascendencia por lo individual, lo personal, subjetivo y cualitativo, valorando también la diversidad de lenguajes, de códigos y conceptos que se han usado en la propuesta.

\section{Discusión y conclusiones}

El estudiantado ha comprobado, como sostienen Acaso y Megias (2017), que trabajar con lenguajes artísticos contemporáneos implica usar el intelecto y lo manual al mismo nivel, ir más allá de las emociones para entender también la parte conceptual de la obra. Mediante un aprendizaje ligado a la experiencia real vivida, la propuesta consigue conectar y motivar al alumnado. Así comprenden, como afirma Caeiro-Rodríguez (2018), la importancia de la Educación Artística no solo aplicada a la enseñanza formal, también hacia la vivencial y experiencial. Teniendo en cuenta las aportaciones de Munari (2018), la propuesta ha despertado en el alumnado el interés por el uso de la fantasía y la imaginación como motor creativo. Esto va unido al estímulo que supone trabajar con el objeto cotidiano, los recuerdos y las experiencias, que producen en el estudiantado un crecimiento personal más allá del académico (Martín-Piñol y Calderón-Garrido, 2021).

Esta investigación ha fortalecido nuevos planteamientos creativos y técnicas de información que recapacitan sobre los diferentes tipos de lenguajes y herramientas que se deben utilizar para transmitirlos. Un enfoque didáctico que ha facilitado la adquisición de contenidos vinculados a la materia, a los procesos de creación y al contexto social-cultural, trabajando primero con fines casi documentales y después con fines expresivos. Con la experiencia vivida, se consigue mezclar realidad y ficción, al igual que en la novela. Las actividades relacionadas con el dibujo permiten conseguir una representación de la realidad objetiva y, con aquella relacionada con la escultura, una presentación de la realidad objetual (Marchán, 1990). 
La propuesta no ha sido estática, pues con la imaginación se han construido imágenes en nuestra mente, sobre el papel y los objetos, a partir de palabras, recuerdos. Mientras que con el dibujo de imitación el alumnado se hubiera limitado a copiar, con esta estrategia se consigue un dibujo que se adapta a la propia percepción del estudiantado (Puente, 1989). Se entiende así el dibujo como educación visual, un medio para reflexionar y visualizar los signos del libro y de la realidad confinada. Y es que la expresión, como afirma Arnheim (2005), "es el contenido primario de la visión en la vida cotidiana, con tanta mayor razón lo será de la manera de mirar el mundo del artista" (p. 460).

La imaginación se usa para transformar palabras e ideas en producciones concretas, dibujos y creaciones objetuales que desarrollan una historia. Cabe destacar la predisposición del alumnado para utilizar su imaginación con curiosidad y ofrecer representaciones no solo descriptivas, también creativas, consiguiendo riqueza en sus resultados finales. Ahora el concepto de dibujo añade nuevas dimensiones que crean procesos dinámicos donde el grafismo emerge con las características propias del lenguaje (Rabazas-Romero, 2000).

Este artículo cuestiona el espacio docente y fija la vista en la habitación como laboratorio. Un lugar que, en contexto no pandémico, sobre todo para adolescentes y universitarios, supone un espacio de recogimiento, intimidad y libertad; cuatro paredes que poseen un matiz similar al del estudio de un artista. Pero que en este escenario de confinamiento también puede derivar en problemas de salud mental, soledad, ansiedad, descontrol emocional, abuso del uso de dispositivos electrónicos o motivos de falta del autocontrol (Gómez-Becerra et al., 2020; Li et al., 2021). Ese factor personal convierte a la habitación en un catalizador de emociones y conexión con uno mismo haciéndola perfecta para desarrollar actividades de carácter artístico, imaginativo y reflexivo, algo que, en el aula y con los compañeros, se queda a veces mermado por vergüenzas o miedos. 
Para que la experiencia didáctica cobre sentido en su totalidad, conceptual y metodológicamente, el alumnado debe actuar como un artivista, concepto que surge de las palabras "arte" y "activismo". Se transforma en un artista comprometido con los procesos creativos que acompañan la experiencia, posicionando su pensamiento y creaciones hacia el contexto donde actúa (Mesías-Lema, 2018). Ahora hay que invadir los espacios confinados, las habitaciones, los hogares y los espacios digitales. De este modo, se consigue reflexionar sobre la utilidad del arte como lenguaje social, herramienta educativa y como medio de comunicación (Aladro-Vico et al., 2018).

Convendría redescubrir lo que aporta el dibujo, dando énfasis al verbo descubrir, ya que, tanto en artes como en educación, el verbo enseñar bien podría sustituirse por este. Dibujar es un acto cargado de imaginación, pero también de comprensión de lo dibujado, pues nuestra manera de representar nos ayuda a entender la relación con las cosas, el mundo y nuestro yo. Como decía Berger (2012): "dibujar es una forma de indagar. Y el primer impulso genérico a dibujar se deriva de la necesidad humana de búsqueda, de marcar ciertos puntos, de situar las cosas y situarse uno mismo" (p. 160).

Los resultados nos hacen dirigir la mirada hacia el terreno de lo subjetivo, dada la variedad de visiones y propuestas, enlazando con una serie de características del dibujo contemporáneo:

- $\quad$ El referente no es necesariamente externo, no va ligado a mímesis.

- Control del dibujo. Si lo importante es el objeto, proyectaremos la mejor solución para representarlo.

- El sujeto descubre su propia capacidad formativa desarrollando su propio lenguaje.

- Descontextualización. 
- El dibujo se identifica con el pensamiento. La relación mente-papel es directa y fluida.

- Apertura del dibujo a conceptos como la improvisación, la intuición o la estrategia.

- El dibujo vinculado a la emoción. Huella de una inquietud, sentimiento o sensación.

- El gesto por el gesto. La importancia de los recursos gráficos por sí solos.

- El dibujo ligado a los cinco sentidos.

- Huida de lo académico como único sistema de representación.

- Dibujo no sistemático que crea sus propias reglas durante el proceso.

- El dibujo como lenguaje en sí mismo. Instrumento de reflexión, vehículo de expresión y comunicación.

- La fragmentación como composición.

- Incorporación de nuevos códigos y significados, sea de fuera o surgidos durante el devenir de la obra.

- Autonomía. El dibujo ya no funciona como acción previa, sino que es un fin en sí mismo.

- Interdisciplinariedad

- El dibujo como campo de pruebas.

Por último, cabría mencionar que esta metodología queda sujeta a futuras mejoras, siendo interesante como docentes e investigadores anticiparse a una recogida de datos más concreta o a una participación amplia de estudiantes que propicie un mayor número de resultados. No obstante, entendemos que esta propuesta se diseñó e implementó en unas circunstancias singulares $y$, aunque se realizaran las mismas prácticas bajo el mismo contexto de la habitación, no se contaría con la influencia de aquel momento social que supone una pandemia. 


\section{Referencias}

Acaso, M. (2107). rEDUvolution. Hacer la revolución en la educación. Paidós.

Acaso, M. y Megías, C. (2017). Art Thinking. Cómo el arte puede transformar la educación. Paidós.

Adorno, Th. W. (2007). El esquema de la cultura de masas. En Obra completa 3 (pp. 281-315). Akal.

Aladro-Vico, E., Jivkova-Semova, D. y Bailey, O. (2018). Artivism: A new educative language for transformative social action. [Artivismo: Un nuevo lenguaje educativo para la acción social transformadora]. Comunicar, 57, 09-18. https://doi.org/10.3916/C57-2018-01

Arnheim, R. (1993). Consideraciones sobre la educación artística. Paidós.

Arnheim, R. (2005). Arte y percepción visual. Psicología del ojo creador. Alianza Editorial.

Barone, T., \& Eisner, E. (2012). Arts Based Research. Sage Publications.

Barro, D. (2012). Luis Gordillo. Quitando arrugas a la pintura. Dardo Magazine, 19/20, 28-41.

Barthes, R. (1982). Lo obvio y lo obtuso, Imágenes, gestos, voces. Paidós Comunicación.

Baudrillard, J. (2012). El complot del arte. Ilusión y desilusión estéticas. Amorrortu Editores. https://doi.org/10.5565/rev/qp.284

Benjamin, W. (2012). La obra de arte en la época de su reproducción mecánica (3ª Ed.). Casimiro Libros.

Berger, J. (2009). Algunos pasos hacia una pequeña teoría de lo visible. Árdora Ediciones.

Berger, J. (2012). El cuaderno de Bento. Alfaguara.

Borrero, M. C. (2021). Historias que teje la pandemia: proyectos artísticos creativos en tiempos de crisis. (pensamiento), (palabra). Y obra, (25). 92-117. https://doi.org/10.17227/ppo. num25-12298

Breton, A. (1992). Manifiestos del surrealismo. Editorial Labor.

Bru, M. (2015). El concepto de big bang como inicio del proceso creativo del dibujo. Opción, 31(4), 147-159. https://produccioncientificaluz.org/index.php/opcion/article/ view/20543/20454 
Caeiro-Rodríguez, M. (2018). Aprendizaje basado en la creación y educación artística: proyectos de aula entre la metacognición y la metaemoción. Arte, Individuo y Sociedad, 30(1), 159 177. http://dx.doi.org/10.5209/ARIS.

Cano, R. y Tovar, I. (1995). A través del dibujo. Junta de Andalucía, Consejería de Cultura.

Cánovas, C. E. (2015). La perspectiva crítica en la educación: su vigencia en el contexto neoliberal. Revista Internacional de Educación para la Justicia Social, 3(1), 174-190. https:// bit.ly/3tZLXgC

Chávez, J. D. (2013). El interior expuesto. Sobre la habitación de Van Gogh en Arlés (óleo sobre lienzo, 72 x 90 cm, 1888). Iconofacto, 9(12), 193-213. http://hdl.handle. net/20.500.11912/7348

Costa-Rodríguez, C., Palma-Leal, X. y Salgado, C. (2021). Docentes emocionalmente inteligentes. Importancia de la Inteligencia Emocional para la aplicación de la Educación Emocional en la práctica pedagógica de aula. Estudios Pedagógicos, 47(1), 219-233. http://dx.doi. org/10.4067/S0718-07052021000100219

D. K. Ching, F. (2012). Dibujo y proyecto. Gustavo Gili.

De la Torre, S. (2003). Dialogando con la creatividad. De la identificación a la creatividad paradójica. Octaedro.

De Maistre, X. (2007). Viaje alrededor de mi habitación. Funambulista.

Eco, U. (2006). Apocalípticos e integrados. Editorial Lumen y Tusquets Editores.

Efland, A. D., Freedman, K. y Stuhr, P. (2003). La educación en el arte posmoderno. Ediciones Paidós Ibérica.

Emin, T. (1995). Everyone $i$ have ever slept with 1963-1995 [Instalación artística]. Londres, The Saatchi Gallery.

Emin, T. (1998). My bed [Instalación artística]. The Saatchi Gallery.

Escobar, I. (2000). Dibutades o el arte de dibujar. Arte, Individuo y Sociedad, 12, 241-271. https://revistas.ucm.es/index.php/ARIS/article/view/ARIS0000110241A 
Extremera, N. (2020). Coping with the stress caused by the COVID-19 pandemic: future research agenda based on emotional intelligence. [Afrontando el estrés causado por la pandemia COVID-19: futura agenda de investigación desde la inteligencia emocional). International Journal of Social Psychology, 35(3). 631-638. https://doi.org/10.1080/02134748.2020.178 3857

Fernández, M. B.y Johnson, D. (2015). Investigación-acción en formación de profesores: Desarrollo histórico, supuestos epistemológicos y diversidad metodológica. Psicoperspectivas, 14(3), 93-105. 10.5027/PSICOPERSPECTIVAS-VOL14-ISSUE3-FULLTEXT-626

Friedenthal, R. (1963). Cartas de grandes artistas (Tomo 1). Nauta Ediciones.

Gómez, J. J., Cabezas, L. y Bordes, J. (2003). El manual de dibujo. Estrategias de su enseñanza en el siglo XX. Cátedra.

Gómez-Becerra, I., Flujas, J. M., Andrés, M., Sánchez-López, P. y Fernández-Torres, M. (2020). Evolución del estado psicológico y el miedo en la infancia y adolescencia durante el confinamiento por la COVID-19. Revista de Psicología Clínica con Niños y Adolescentes, 7(3), 11-18. doi: 10.21134/rpcna.2020.mon.2029

Hernández, F., Aberasturi, E., Sancho, J. M. y Correa, J. M. (Eds.). (2020). ¿Cómo aprenden los docentes? Tránsitos entre cartografías, experiencias, corporeidades y afectos. Octaedro.

Hopper, E. (1952). Morning sun [Pintura]. Columbus, Columbus Museum of Art.

Hopper, E. (1961). A woman in the sun [Pintura]. Nueva York, Whitney Museum of American Art.

Irwin, R., \& De Cosson, A. (Eds.). (2003). A/r/tography. Rendering Self Through Arts-Based Living Inquiri. Pacific Educational Press.

Jenny, P. (2013). La mirada creativa. Editorial Gustavo Gili.

Jiménez, I. (2009). El dibujo invisible. Dibujando para crear el dibujo. Fabrikart, 8, 124-140. https://www.ehu.eus/ojs/index.php/Fabrikart/article/view/1490/1132

Lambert, S. (1996). El dibujo. Técnica y utilidad. Hermann Blume.

Latorre, A. (2003). La investigación acción: Conocer y cambiar la práctica educativa. Graó.

León, O. y Montero, I. (2015). Métodos de investigación en Psicología y Educación: Las tradiciones cuantitativa y cualitativa. McGraw-Hill. 
Li, J., Zhan, D., Zhou, Y., \& Gao, X. (2021). Loneliness and problematic mobile phone use among adolescents during the COVID-19 pandemic: The roles of escape motivation and self-control. Addictive behaviors, 118. https://doi.org/10.1016/j.addbeh.2021.106857

Maiso, J. (2019). Socialización capitalista y mutaciones antropológicas. Adorno, el nuevo tipo humano y nosotros. Con-Ciencia Social (segunda época), 2, 65-80.

Marchán, S. (1990). Del arte objetual al arte de concepto. Epílogo sobre la sensibilidad "postmoderna". Akal/Arte y estética.

Martín, F. (2002). Contribuciones para una antropología del diseño. Gedisa.

Martín-Piñol, C. y Calderón-Garrido, D. (2021). Del objeto descubierto al objeto artístico, un planteamiento con propósitos educativos. Arte, Individuo y Sociedad, 33(2), 467-483. https://doi.org/10.5209/aris.68512

Mesías-Lema, J. (2018). Artivism and social conscience: Transforming teacher training from a sensibility standpoint. [Artivismo y compromiso social: Transformar la formación del profesorado desde la sensibilidad]. Comunicar, 26(57), 19-28. https://doi.org/10.3916/C572018-02

Moreno, J. M. (2010). Autocrítica del arte. Barataria.

Munari, B. (2016). ¿Cómo nacen los objetos? Gustavo Gili.

Munari, B. (2018). Fantasía. Invención, creatividad e imaginación en las comunicaciones visuales. Gustavo Gili.

Murillo, F. J. y Duk, C. (2020). El Covid-19 y las Brechas Educativas. Revista latinoamericana de educación inclusiva, 14, 11-13. 10.4067/S0718-73782020000100011

Ordine, N. (2013). La utilidad de lo inútil. Acantilado.

Ovejero, F. (2014). El compromiso del creador. Ética de la estética. Galaxia Gutenberg. Círculo de Lectores.

Pérez-Valero, M. (2016). Sugestiones poéticas, una imagen a la deriva. El artista indócil y la trampa irónica de los signos (tesis doctoral). Editorial Universidad de Granada. http://hdl. handle.net/10481/44615

Prados, M. E., Márquez, M. J. y Padua, D. (2018). Otra pedagogía en movimiento. Dialogando con la experiencia en la formación inicial. Edit. Universidad de Almería. 
Puente, J. R. (1989). Dibujo y Educación Visual. Curso para la enseñanza media superior. Gustavo Gili.

Rabazas-Romero, A. (2000). Del dibujo de objetos al dibujo como objeto. El modelo de Beuys. Arte, Individuo y Sociedad, 12, 185-227. https://revistas.ucm.es/index.php/ARIS/article/ view/ARIS0000110185A

Salido-López, P. V. (2017). La Educación Artística en el contexto de las competencias clave: del diseño a la evaluación de talleres didácticos en la formación de formadores. Arte, Individuo y Sociedad, 29(2), 349-368. http://dx.doi.org/10.5209/ARIS.54655

Simondon, G. (2013). Imaginación e invención. Ediciones La cebra y Editorial Cactus.

Soto-Romero, M. (2008). Educating the sight and the audiovisual writing. [Educar la mirada y la escritura audiovisual]. Comunicar, 31. https://doi.org/10.3916/c31-2008-03-045

Cómo citar: Pérez-Valero, M. y Bru, M. (2022). Herramientas de acción-investigación artística durante el confinamiento por Covid-19 a partir de la obra Viaje alrededor de mi habitación de Xavier de Maistre. Revista KEPES, 19(25), 463-498. https://doi.org/10.17151/kepes.2022.19.25.16 